Elvio Juanito

Marques de Olivei-

ra Júnior

É pós-graduando em

Comunicação Empresa-

rial e Marketing Digital

pela Unicesumar.

Liana Vidigal Rocha

Docente do Curso de Jornalismo e do Programa de Pós-graduação em Comunicação e Sociedade da Universidade Federal do Tocantins.

Líder do Grupo de

Pesquisa em Jornalismo e Multimídia (CNPq).

\section{Da cibercultura ao ciberativismo: os povos indígenas do Tocantins no Facebook}

\author{
The cyberculture at \\ cyberactivism: indigenous \\ peoples of Tocantins \\ on Facebook \\ La cibercultura en \\ ciberativismo: pueblos \\ indígenas de Tocantins \\ en Facebook
}




\section{RESUMO}

Verifica-se a Cibercultura e o Ciberativismo diante dos povos indígenas do Tocantins e como estes, ao integrarem o universo digital, tal como o das redes sociais, reforçam suas práticas culturais e reafirmam seus anseios. Todavia, utiliza-se como método a Análise de Conteúdo, para uma melhor interpretação de perfis e páginas do Facebook, descritos como pertencentes a estes nativos indígenas. Mediante a isso, embora prevaleça o equívoco de que esses povos não se transformam ou de que suas culturas estão "congeladas", é possível, ao realizar esta análise, perceber o contrário, visto que eles estão se apropriando de novas perspectivas tecnológicas e passam, portanto, a redimensionar e modificar suas tradições culturais, sem perder o ethos indígena.

Palavras-chave:Cibercultura; Ciberativismo; Facebook; Indígenas; Tocantins.

\section{ABSTRACT}

It is observed that Tocantins indigenous peoples see Cyberculture and Cyber-activism as they integrate the digital universe, using tools such as social networks, they reinforce their cultural practices and reaffirm their aspirations. Hence, it is used as method of Content Analysis, profiles and Facebook pages for a better interpretation, described as belonging to these indigenous natives. Even though the ambiguity that these peoples do not change prevails or that their cultures are "frozen", by fulfilling this analysis, it is possible to perceive the opposite. Since they are appropriating new technological perspectives, they are therefore re-dimensioning and modifying their cultural traditions, without losing the indigenous ethos.

Keywords: Cyberculture; Cyberactivism; Facebook; Indigenous People; Tocantins.

\section{RESUMEN}

Hay una Cibercultura y Ciberativismo antes de que las poblaciones indígenas de Tocantins y como estos, para integrar el universo digital, como las redes sociales, reforzar sus prácticas culturales y reafirman sus deseos. Sin embargo, es usado como un método de análisis de contenido, para una mejor interpretación de los perfiles y páginas de Facebook, descrito como pertenecientes a estos pueblos nativos. Por esto, aunque no es errónea la idea de que estas personas no se transforman - que sus culturas son "congelados", para llevar a cabo este análisis, es posible darse cuenta de lo contrario. Ya que se están apoderando de nuevas perspectivas tecnológicas y son, por lo tanto, cambiar el tamaño y modificar sus tradiciones culturales, sin perder el espíritu indio.

Palabras clave: Cibercultura; Ciberativismo; Facebook; Pueblos Indígenas; Tocantins. 


\section{Introdução}

As novas práticas, atitudes e valores no meio digital foram chamados de Cibercultura e se desenvolveram juntamente com o crescimento do ciberespaço (LÉVY, 1999), rodeado, portanto, por tecnologias, aliado à sociedade e à cultura (LEMOS, 1997).

O universo social [físico] e o digital tornaram-se cada vez mais interligados. Com isso, os chamados ativistas sociais também tiveram que se adaptar e, assim, encontraram diferentes formas de manifestações graças à força do cenário digitalizado, com novas possibilidades comunicacionais e a proliferação das diversas formas de ativismo através da internet (COELHO e COSTAS, 2013), como movimentos de camponeses, mulheres, trabalhadores, negros, índios, entre outros grupos e organizações sociais. Este novo contexto no "local digital" passou a ser nomeado de ativismo digital ou ciberativismo.

Nesse sentido, este artigo procura explicitar que os indígenas não estão alheios às tecnologias ou aos meios de comunicação, como prevalece no discurso social. Ao se apropriarem desses novos contextos

A tese de Eliete Pereira (2013, p.67) traz como definição o "local digital" que significa "uma forma de "fazer espaço" no digital, tessitura de espacialidades comunicantes no habitar, no entrelugar digital (...)". 
interativos, esse grupo social não perde suas formas culturais ou é "contaminado", como se costuma afirmar, mas mostra que suas culturas estão sendo redimensionadas e transformadas.

Os indígenas, historicamente, são os primeiros desbravadores desse ativismo digital, juntamente com os camponeses ainda no Movimento Zapatista. A partir disso, o presente discute o conceito de cibercultura e de ciberativismo, entrelaçando estes conceitos com a Nova Ancoragem das Tradições ${ }^{2}$ (THOMPSON, 2008) dos indígenas diante aos cenários tecnológicos e comunicacionais atuais.

Com o intuito de identificar essa nova realidade diante do contexto sociocultural no Tocantins, é feita uma análise de páginas no Facebook (fanpages) e perfis de povos indígenas presentes no Estado, tais como Akwe-Xerente, Pankararu, Karajá e Javaé. Porquanto, para melhor compreensão das abordagens, é utilizado o método de Análise de Conteúdo, especialmente das postagens de janeiro a abril de 2017, por meio de três fases (BARDIN, 1977): pré-análise, análise do material e tratamento dos resultados (inferência e interpretação).

\section{Conectados: o ethos indígena na web}

As transformações provocadas pela cibercultura englobam também as comunidades indígenas, vistas antes como tradicionais, no sentido mais estereotipado possível, como culturas "congeladas" ou "atrasadas". Os nativos indígenas, como todos os grupos

2 Thompson (2008, p. 60) ao defender a nova ancoragem da tradição, afirma que as tradições estão se ancorando em novos ambientes comunicacionais, 
sociais, passaram por transformações ${ }^{3}$ continuam a ser indígenas, sem perder o ethos ${ }^{4}$. Portanto, não podemos falar de perda cultural ${ }^{5}$ e nem mesmo que a cultura nativa é congelada. Isto é um equívoco, explicado por José Ribamar Bessa Freire, no texto "Cinco ideias equivocadas sobre os índios":

(...) o brasileiro pode usar coisas produzidas por outros povos - computador, telefone, televisão, relógio, rádio, aparelho de som, luz elétrica, água encanada - e nem por isso deixa de ser brasileiro. Mas o índio, se desejar fazer o mesmo, deixa de ser índio? É isso? Quer dizer, nós não concedemos às culturas indígenas aquilo que queremos para a nossa: o direito de entrar em contato com outras culturas e de, como consequência desse contato, mudar (FREIRE, 2000, p. 12-13).

As culturas indígenas, todavia, estão se transformando e se apropriando das novas perspectivas, e assim adquirem outras formas culturais, sem que isso tenha qualquer implicação em determinados grupos étnicos (BARTH, 1995). A globalização e o capitalismo não estão destruindo e homogeneizando as culturas, mas sim gerando novas formas culturas (SAHLINS, 1997). Segundo Stuart Hall (2006, p.8), "(...) as identi-

3 Thompson (2008, p.160) confirma que "... as tradições mesmas foram transformadas à medida que seu conteúdo simbólico foi sendo assumido pelos novos meios de comunicação". Portanto, "pensar esses rituais contemporâneos implica em pensar as transformações contemporâneas dos coletivos indígenas em virtude da crescente interação com as sociedades nacionais" (DEMARCHI, 2014, p 30).

4 "O ethos de um povo é o tom, o caráter e a qualidade de sua vida, seu estilo moral e estético, e sua disposição é atitude subjacente em relação a ele mesmo e ao seu mundo que a vida reflete" (GEERTZ, 2015, p. 93).

5 As tradições não correm o risco de "perder suas raízes" (THOMPSON, 2008). 
dades estão sendo 'descentradas', isto é, deslocadas ou fragmentadas". Desta forma, as identidades são, pois, líquidas (BAUMAN, 2003) e estão em constantes mudanças. São as chamadas "culturas híbridas" (CANCLINI, 1997). E o universo digital contribui para com essas transformações sociais e culturais.

Desta forma, as culturas indígenas na contemporaneidade passam a estar interconectadas, interligadas, em "redes" (CASTELLS, 2001), criando assim novos canais de interação social, que colaboram no surgimento de novos ambientes socioculturais.

(...) não devemos cair no equívoco de julgar que as transformações culturais são devidas apenas ao advento de novas tecnologias e novos meios de comunicação e cultura. São, isto sim, os tipos de signos que circulam nesses meios, os tipos de mensagens e processos de comunicação que neles se engendram os verdadeiros responsáveis não só por moldar o pensamento e a sensibilidade dos seres humanos, mas também por propiciar o surgimento de novos ambientes socioculturais (SANTAELLA, 2003, p. 23).

Ao falar desse novo ambiente sociocultural, é importante lembrar que no Brasil a participação desses povos nativos na internet só surgiu em 2001, como afirma a pesquisa ${ }^{6}$ de Eliete da Silva Pereira, em seus estudos sobre os indígenas e suas relações com as novas tecnologias. Apesar da crescente, embora mi-

6 Apesar de existir uma escassez sobre a história das tecnologias nas aldeias, a Pesquisa Nacional por Amostra de Domicílios (PNAD) de 2001 e da amostra do Censo Demográfico 2000, ambas levantadas pelo IBGE, pelo Centro de Políticas Sociais da Fundação Getúlio Vargas identificou ainda a taxa de 3,72\% de acesso digital das populações indígenas de um total de $12,46 \%$ da população brasileira que dispõe de acesso ao computador e $8,31 \%$ de Internet (PERREIRA, 2008). 
noritária, presença indígena brasileira no ciberespaço, estes povos se reconstroem e se reelaboram etnicamente nas redes digitais (PEREIRA, 2008).

Desde então, os indígenas do Brasil vêm aderindo ao novo ambiente digital, "(...) de lá para cá essas formas de comunicação na rede se transformaram em sites, blogs, comunidades virtuais (principalmente do Orkut) e portal" (PEREIRA, 2008, p. 5). Na verdade, os "'índios eletrônicos' ainda representam uma pequena minoria, tratando-se de uma tecnologia dificilmente acessível à maioria das comunidades indígenas" (GALLOIS e CARELLI, 1998, p. 1).

\section{Na conexão da Cibercultura}

O novo ambiente social que se formou utiliza as tecnologias e suas ferramentas para provocar, entre outras coisas, um "compartilhamento de emoções, de convivialidade e de retorno comunitário" (LEMOS, 1997, p.4), numa relação, pois, entre a sociedade, a cultura e as novas tecnologias, "que surgiram com a convergência das telecomunicações com a informática na década de 70" (LEMOS, 2005, p. 1). Esta é a cibercultura, com novas maneiras de se relacionar com outro e até mesmo com o mundo. "A cibercultura representa a cultura contemporâneas sendo consequência direta da evolução da cultura técnica moderna" (LEMOS, 2005, p. 1 e 2).

A cibercultura" é, em poucas palavras, a "socialidade na técnica e a técnica na socialidade" (LEMOS, 1997, p.4), que é definida ainda como um "conjunto de técnicas (materiais e intelectuais), de

"As realidades compartilhadas, que podem fazer comunicar milhares ou mesmo milhões de pessoas devem ser consideradas como dispositivos de comunicação "todos-todos", típicos da cibercultura" (LÉVY, 1999, p.98). 
práticas, de atitudes, de modos de pensamento e de valores" (LÉVY, 1999, p. 17). E como complementa Rüdiger (2011, p. 60). "A cibercultura se movimenta sobre o pano de fundo da paulatina expansão do mundo da informática e, por tudo o que dissemos" (RÜDIGER, 2011, p.60). Com isso, a cibercultura se desenvolveu juntamente com o crescimento do ciberespaço. "Eu defino o ciberespaço como o espaço de comunicação aberto pela interconexão mundial dos computadores e das memórias dos computadores" (LÉVY, 1999, p.85-86).

O termo ciberespaço popularizou-se com a rápida expansão do número de usuários da rede na década de 1990 (FRAGOSO, 2000). Proporcionalmente, surgem as chamas comunidades virtuais, que "parecem ser um excelente meio (entre centenas de outros) para socializar, quer suas finalidades sejam lúdicas, econômicas ou intelectuais, quer seus centros de interesse sejam sérios, frívolos ou escandalosos" (LÉVY, 1999, p.132). E tornou-se um conjunto de informações que transitam nos servidores e terminais conectados à internet.

Esse novo espaço social é repleto de infraestrutura de redes telemáticas interligando computadores e relacionando humanos e não humanos, formando e deformando. É justamente esse espaçamento produzido por lugares, coisas, pessoas e objetos conectados (LEMOS, 2013), sempre em construção. Dentro desse ciberespaço ou da cibercultura, não há mais uma diferenciação ou separação entre as pessoas e as tecnologias. Elas agora se compõem e estão intrinsecamente relacionadas. A Rede, pois, não é infraestrutura, não é por onde as coisas passam, mas aquilo que se forma na relação entre humanos e não humanos. 
Rede é aqui um conceito dinâmico. Não é o que conecta, mas o que é gerado pelas associações. Não é algo pronto, por onde coisas passam, mas o que é produzido pela associação ou composição de atores humanos e não humanos (LEMOS, 2013, p.53).

Ainda de acordo Lemos (2013), é uma dinâmica dos fenômenos emergentes que cercam a vida digital com a compreensão dos artefatos tecnológicos como mediadores e não como meras ferramentas nos processos de mediação. Os indígenas, ao fazerem parte desse universo digital, o utilizam como cenário para reivindicações, anseios e lutas, muitas vezes reforçando o discurso pela preservação das tradições culturais. Eis que surge o ciberativismo indígena, isto é, mesmo estando em espaços diferentes, provocados pelo digital, os indígenas compartilham, na sua grande maioria, dos mesmos pensamentos.

\section{Navegar e manifestar: eis o ciberativismo}

Os ativistas sociais viram que as manifestações apenas nas ruas das cidades não teriam as mesmas proporções e resultados sem antes ir ao encontro do digital e mobilizar ou sensibilizar as pessoas que ali estavam, com os mais variados objetivos. A busca por democracia, desde o surgimento da internet, tem outra dimensão. Sua presença se faz necessária primeiramente no digital para em seguida ir ao social, ou, quem sabe, haja a convergência de ambos em um mesmo tempo com diferentes espaços.

O ciberativismo é a uma forma de ativismo através da internet, ainda que seja necessária a existência do ativismo real. Utilizado, principalmente, por grupos politicamente ativos, essa forma de ativismo é realizada com a intenção de divulgar e abrir espaços para 
determinadas causas e possíveis discussões sobre os assuntos. Além disso, aqueles que utilizam dessa prática acreditam que essa seja uma alternativa aos meios de comunicação em massa tradicional (RESENDE et al, 2015, p.3).

O ciberespaço seria, por sua vez, este encontro de diversos povos, grupos e pessoas que interagem entre si e poderiam ali, também, se expressarem e se manifestarem. Um dos primeiros movimentos sociais, por meio da internet, é o movimento zapatista no século XX - janeiro de 1994, no estado de Chiapas, no México - que teve como manifestantes as populações indígenas e camponesas. "(...) Se transformou num movimento com repercussões transnacionais inaugurado por ações comunicativas viabilizadas pelos circuitos digitais" (PEREIRA, 2007, p. 50). O grito de "Ya basta!" (Já basta!) era justamente em oposição às situações precárias em que viviam essas populações.

O Já Basta! do Exército Zapatista de Libertação Nacional (E.Z.L.N), em janeiro de 1994, escancarou o racismo existente nas relações com o Estado e com a sociedade como um todo, as precárias condições de vida das comunidades indígenas no país, assim como a farsa de um projeto hegemônico neoliberal que, "desde arriba", pretendia modernizar a nação (SÁNCHEZ, 2015, p. 217).

O movimento, mesmo sem saber, se torna um movimento de ativismo digital ou ciberativismo. E os indígenas, seus precursores. Eles não tinham como objetivo a tomada de poder, nem mesmo a constituição de um partido político, mas buscavam um diálogo permanente em prol da democracia. Mais tarde, outros movimentos conectados por redes surgem na Europa e nos Estados Unidos, contra os sistemas cor- 
ruptos dos governos, além da Grécia e Itália, com mobilizações de mulheres (CASTELLS, 2013) também em prol da democracia. Entre os mais conhecidos está o movimento Occupy Wall Street, nos Estados Unidos.

(...) tão espontâneo quanto os outros e igualmente conectado em redes no ciberespaço e no espaço urbano, tornou-se o evento do ano e afetou a maior parte do país, a ponto de a revista Time atribuir ao "Manifestante" o título de personalidade do ano. (...) em outubro de 2011, uma rede global de movimentos Occupy, sob a bandeira "Unidos pela Mudança Global", mobilizou centenas de milhares de pessoas (...) de 82 países, reivindicando justiça social e democracia verdadeira (CASTELLS, 2013, p. 11 - 12).

A proliferação dessas manifestações digitais inclui pessoas de todas as idades e condições. Estas passaram, posteriormente, a ocupar o espaço público, num encontro às cegas entre si, reivindicando seus direitos (CASTELLS, 2013), como aconteceu no Brasil. O Movimento Passe Livre (MPL), em 2013, começou a ser organizado na internet, sendo mais específico por meio das redes sociais, e em seguida foi para as ruas. Primeiramente contra o aumento da passagem do transporte, no decorrer das reivindicações surgiram temas como igualdade e melhores condições de vida.

De forma generalizada, pode-se dizer que as mídias sociais foram fundamentais para garantir visibilidade às lutas contra as numerosas injustiças sociais promovidas pelos governos autoritários nos países (...). Já nos protestos do Brasil, a web foi amplamente utilizada para a troca de informações, sobretudo para evidenciar formas de abuso de poder dos governos e da polícia, organizar e repercutir os protestos e criticar a cobertura dos media (ROSSINI, 2014, p. 317 - 318). 
Desta forma, o ativismo digital busca, entre outras coisas, o "apoio e mobilização para uma causa; criar espaços de discussão e troca de informação; organizar e mobilizar indivíduos para ações e protestos on-line e off-line" (RIGITANO, 2003, p.3). Sandor Vegh (2003, p. 71), no livro "Classifying forms of online activism: the case of cyberprotests against the World Bank" afirma que "entende-se por ciberativismo a utilização da internet por movimentos politicamente motivados". Vegh propõe ainda três categorias de classificação do ativismo on-line, sendo a primeira a Conscientização e apoio, na qual a internet pode funcionar como uma fonte alternativa de informação. A partir desta obtenção de informações, por meio de visitas a sites, os ativistas podem se inscrever em listas de discussões ou participarem de fóruns. A segunda classificação diz respeito à organização e mobilização, que nascem a partir da Internet e partem para uma determinada ação, que pode ser on-line ou offline. Por último, esse ativismo é formado pelas iniciativas de ação/reação, mais conhecidas por "hacktivismo", ou ativismo hacker".

E é nas redes sociais" que este tipo de ativismo digital se faz mais presente, principalmente no Face-

8 Entre outras coisas, o ativismo hacker é uma resposta à sociedade de controle. Como explica Machado (2015, p. 1536), "Dia após dia, hacktivistas se unem para, entre inúmeras outras ações: furar bloqueios indesejáveis; libertar informações de interesse público; promover a proteção da privacidade dos internautas; criptografar comunicações; desenvolver softwares inclusivos, cujo uso independa de empresas; (...) empreender ações digitais diretas em protesto a atos de governos e/ou corporações".

9 Os sites de redes sociais passaram a existir posteriormente ao advento da internet, no final da década de 1990, tendo como pioneiro o site SixDegress (LEMOS; LÉVY, 2010). Mais tarde o Orkut e em seguida, o Facebook. 
book. Desta forma, analisaremos páginas de redes sociais digitais de diferentes povos do Estado do Tocantins e os conteúdos publicados.

\section{Povos indígenas do Tocantins conectados no Facebook}

O Tocantins tem em sua população sete povos indígenas ${ }^{10}$ originários do Estado, sendo eles o povo Karajá, Javaé, Karajá/Xambioá, que formam o povo Iny, Akwe-Xerente, Krahô, Apinajé e Krahô/Kanela, além dos Pankararu e Avá-Canoeiro, sendo estes últimos de outros estados brasileiros, mas que já fazem parte há vários anos dos povos estaduais, mas ainda lutam pela demarcação de terras. Cada um possui seus traços próprios, seus costumes, suas línguas e modos de viver.

Nos últimos anos, acompanhando as mudanças do processo tecnológico, a presença dos indígenas do Tocantins se tornou notável em sites, blogs e redes sociais, ora como processo de interação e canal de acesso às informações, ora como ambiente para dar voz e manifestar suas tradições culturais e anseios. "Dar voz aos índios é permitir que eles expressem, sem tutor, sua posição quanto ao convívio com nossa sociedade" (GALLOIS e CARELLI, 1998, p.4). Estes novos ambientes de comunicação e informação reconstroem e ressiginificam suas particularidades culturais.

Os povos indígenas se fortalecem em situações de comunicação, nas quais as situações particulares fazem sentido e quando eles podem manifestar respostas culturalmente adequadas. O formato de suas culturas de-

10 As informações são do Núcleo de Estudos e Assuntos Indígenas (NEAl) da Universidade Federal do Tocantins, disponível em: <http:// www.uft.edu.br/neai/?page_id=28> Acesso em: 15 jun 2017. 
pende, efetivamente, de uma dinâmica de recriação permanente de diferenças, que assumem como afirmação política e que tem muito a ganhar no acesso aos meios de comunicação. Esta é a verdadeira face do "índio eletrônico" (GALLOIS e CARELLI, 1998, p.3).

Mediante a isso, os povos indígenas, por meio das tecnologias de comunicação e informação, puderam redimensionar suas formas de interação, comunicação, informação e seus modos de viver, indianizando esses elementos centrais do mundo moderno (SAHLINS, 1997), processo denominado pelo mesmo autor de "indigenização da modernidade", que é justamente a maneira como os povos indígenas vêm se elaborando culturalmente e incorporando o sistema mundial ao seu próprio sistema de mundo, isto é, indigenizam a modernidade, adaptam os processos do sistema moderno às suas realidades, e não o contrário:

A modernização, com efeito, não tem sido a única alternativa, sequer na cidade. O efeito inverso, a indigenização da modernidade, é no mínimo tão acentuado quanto o primeiro - na cidade como no campo. Na complexa dialética da circulação cultural entre a terra natal e os lares alhures, as práticas e relações tradicionais ganham novas funções e talvez novas formas situacionais (SAHLINS, 1997, p.114).

Para melhor entender este ciberativismo indígena no Tocantins, foi utilizado o método de Análise de Conteúdo (BARDIN, 1977) sobre as postagens dos anos de 2014, 2015, 2016 e 2017, sendo esse último ano de janeiro a maio, totalizando sete fanpages e perfis analisados, todos no Facebook (Quadro 1). O período foi escolhido já que a grande maioria das páginas e perfis analisados foram criados ou iniciaram as suas publicações em 2014 e intensificaram nos anos recorrentes. Outro dado importante é que, a partir 
de 2012, foi intensificado a presença de computadores nas aldeias indígenas do Tocantins, por meio do "Programa Tocantins Conectado - um computador por aluno"11, do Governo do Tocantins, que entregou diversos computadores portáteis ou notebooks para algumas escolas públicas do Estado, assim como para as unidades escolares indígenas.

Quadro 1: Fan Page/Comunidades/Perfis sobre os indígenas do Tocantins

\begin{tabular}{|c|c|}
\hline Fan Page / Perfil & Links ou Endereços eletrônicos \\
\hline $\begin{array}{l}\text { Nação Xerente- } \\
\text { Tocantínia/TO }\end{array}$ & $\frac{\text { https://web.facebook.com/ }}{\text { nacaoxerente/ }}$ \\
\hline Povo Karajas & $\begin{array}{c}\frac{\text { https://web.facebook.com/ }}{\text { Povo-Karajas-299892923423447/? }} \\
\underline{\text { rdc }=1 \& \text { rdr }}\end{array}$ \\
\hline $\begin{array}{l}\text { Povo Pankararu do } \\
\text { Tocantins }\end{array}$ & $\frac{\frac{\text { https://web.facebook.com/ }}{\text { OVO-Pankararu-Do-Tocantins- }}}{\underline{449451558513197 / \text { ?ref=br rs }}}$ \\
\hline Web Xerente & $\frac{\text { https://web.facebook.com/ }}{\text { edvaldo.akwe/ }}$ \\
\hline Cultura \& Karaja & $\begin{array}{c}\text { https://web.facebook.com/cultura. } \\
\text { karaja/ }\end{array}$ \\
\hline $\begin{array}{l}\text { Aldeia Canoanã } \\
\text { Javaé - Perfil }\end{array}$ & $\begin{array}{c}\text { https://www.facebook.com/ } \\
\text { search/top/?q=aldeia\%20 } \\
\text { canoan\%C3\%A3\%20java\%C3\%A9 }\end{array}$ \\
\hline $\begin{array}{c}\text { Aldeia Salto Kripre - } \\
\text { Perfil }\end{array}$ & $\frac{\text { https://web.facebook.com/ }}{\text { aldeiasalto.kripre?pnref=story }}$ \\
\hline
\end{tabular}

Fonte: Produzido pelos autores

1 A informação pode ser confirmada no site oficial da Secretária de Educação do Estado - Seduc, por meio do link: <http:// secom.to.gov.br/noticia/61 192/> ou ainda em reportagens da imprensa da mídia digital <http://www.ocoletivo.com.br/noticia5372-no-tocantins-governo-entrega-4-500-netbooks-para-auxiliaralunos-no-processo-de-aprendizagem>. 
Entre as comunidades indígenas tocantinenses presentes no Facebook e analisadas nesta pesquisa estão Akwe-Xerente, Karajá, Pankararu e Javaé. A seleção se deu por meio de uma busca na própria rede social e levando em consideração os seguintes critérios: i) a página se refere aos indígenas do Estado do Tocantins; ii) as postagens têm conteúdos sobre indígenas e as informações são verdadeiras; iii) há curtidores nas páginas; iv) O conteúdo tem interação dos internautas, como comentários, curtidas e compartilhamento dos materiais. Para melhor explicar estes resultados, foi detalhado ainda as comunidades indígenas a que a fanpage pertencia, o ano de criação, o número de seguidores e o total de publicações de 2014 a maio de 2017.

Quadro 2 - Detalhamento das páginas analisadas ${ }^{12}$

\begin{tabular}{|c|c|c|c|}
\hline Fan Page/ Perfil & $\begin{array}{c}\text { Comunidade } \\
\text { indígena }\end{array}$ & $\begin{array}{c}\text { Ano de } \\
\text { criação/n de } \\
\text { seguidores }\end{array}$ & $\begin{array}{c}\mathbf{N}^{\circ} \text { de publicações } \\
\mathbf{( 2 0 1 4} \text { a mai/2017) }\end{array}$ \\
\hline $\begin{array}{c}\text { Nação Xerente- } \\
\text { Tocantínia/TO }\end{array}$ & Akwe-Xerente & $\begin{array}{c}2015 / \\
1420 \\
\text { seguidores }\end{array}$ & 75 publicações \\
\hline Povo Karajas & Karajá & $\begin{array}{c}2012 / \\
990 \text { seguidores }\end{array}$ & 59 publicações \\
\hline $\begin{array}{c}\text { Povo Pankararu } \\
\text { do Tocantins }\end{array}$ & Pankararu & $\begin{array}{c}2015 / \\
478 \text { seguidores }\end{array}$ & 42 publicações \\
\hline $\begin{array}{c}\text { Web Aldeias } \\
\text { Xerente }\end{array}$ & Akwe-Xerente & $\begin{array}{c}2017 / \\
26 \text { seguidores }\end{array}$ & 5 publicações \\
\hline $\begin{array}{c}\text { Cultura \& Karajá } \\
157 \text { seguidores }\end{array}$ & Karajá & $\begin{array}{c}2016 / 3 / \\
4820 \text { amigos }\end{array}$ & 57 publicações \\
\hline $\begin{array}{c}\text { Aldeia Canoanã } \\
\text { Javaé - Perfil }\end{array}$ & Javaé & $\begin{array}{c}2016 \\
246 \text { amigos }\end{array}$ & 17 publicações \\
\hline $\begin{array}{c}\text { Aldeia Salto Kripre } \\
\text { - Perfil }\end{array}$ & Akwe-Xerente & \multicolumn{2}{|c|}{} \\
\hline
\end{tabular}

Fonte: Produzido pelos autores

A Coleta de dados foi realizada entre abril a maio de 2017. 
Nas redes "Nação Xerente- Tocantínia/TO" e "Povo Karajás" há um maior número de postagens do que às outras páginas no período analisado. O baixo número de publicações, nas outras páginas, pode estar relacionado a fatores como, a) baixo acesso à internet nas aldeias; b) as postagens são em quantidades menores para não interferirem nos costumes ou rituais; c) a relação com o tempo de postagem para estes nativos indígenas é diferente dos não indígenas que postam diariamente. A "Web aldeias Xerente" é a página com menor número de postagens e interação. Um dos fatores é porque a fan page foi criada no primeiro semestre de 2017.

Figura 1 - Página Nação Xerente - Tocantínia-TO

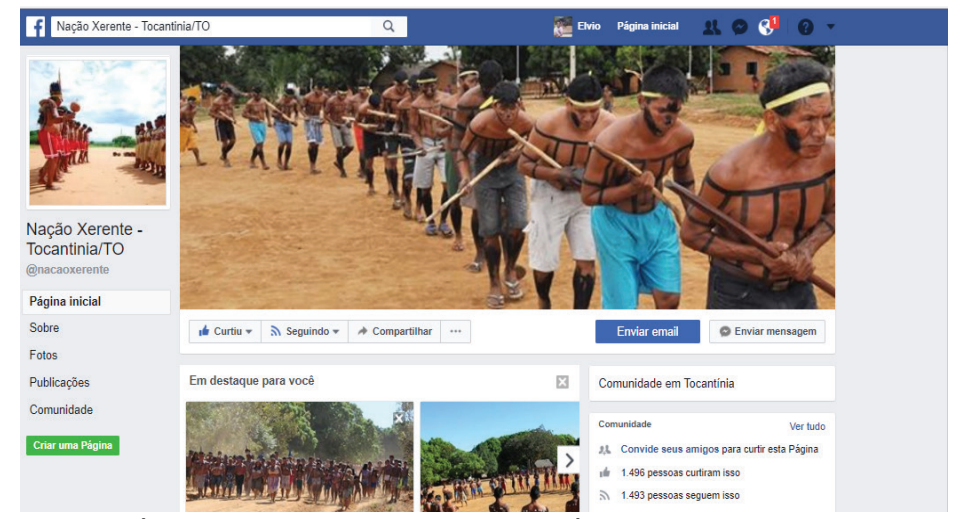

Fonte: Página Nação Xerente - Tocantínia/TO

Diante o exposto, surge o questionamento: esses perfis ou páginas são atualizadas por indígenas? A página Nação Xerente-Tocantínia/TO é feita pelo indígena Srewe Xerente, que confirmou tal informação pelo inbox do Facebook, ao ser questionado diretamente na página. As outras páginas 
não responderam até a conclusão deste artigo, mas utilizam palavras que constatam a presença de indígenas na administração das redes, tais como termos na língua nativa, fotografias e vídeos particulares do cotidiano dos povos e outras.

Figura 2 - Postagem na língua nativa e em Português

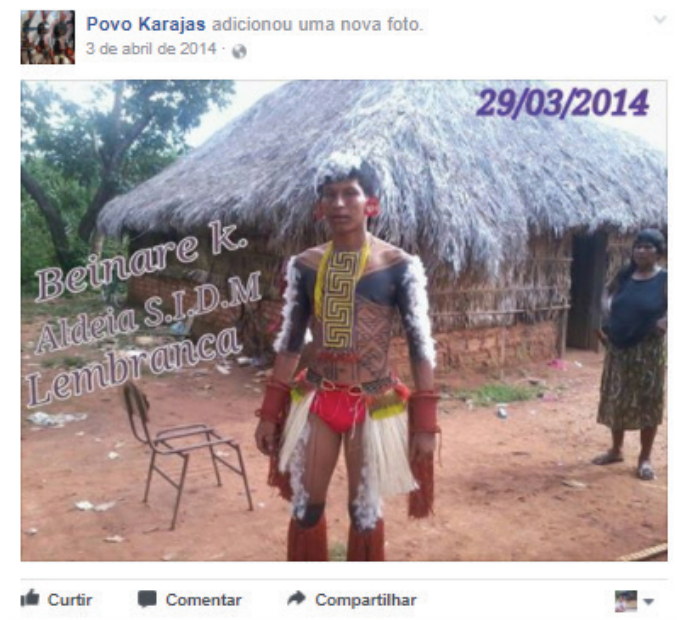

Fonte: Página Povo Karajas

Outro dado importante é que as redes sociais nomeadas "Povo Karajas" e "Aldeia Canoanã Javaé - Perfil" começaram as postagens antes das outras redes, ainda nos anos de 2012 e 2013, respectivamente. Isto pode comprovar que os povos Karajá e Javaé, ambos da família Iny (como se autodenominam), foram os primeiros a divulgar suas culturas e a expressarem seus anseios na rede social no Estado, com um número expressivo de publicações e seguidores no Facebook. Claro que, antes disso, podem ter existido outros perfis ou páginas não identificados aqui. No- 
tavelmente, surgiram com objetivo, inicialmente, de interação com os próprios nativos e até mesmo com os não indígenas, na busca por conhecimento e comunicação, além de divulgação dos seus costumes.

Ora, se um conjunto de técnicas e práticas na internet está atrelado aos modos de viver de determinada cultura, justifica-se, também, a cibercultura perante os nativos indígenas. A figura 2 retrata o uso de tecnologias pelos Javaé, e, consequentemente, o uso da internet, visto que o computador se faz presente.

Figura 3 - Postagem do uso de tecnologias pelos Javaé

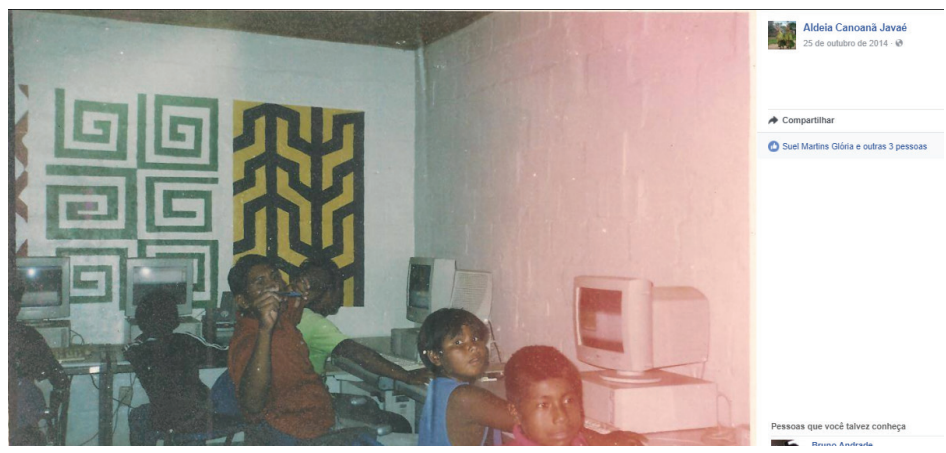

Fonte: Perfil Aldeia Canoanã Javaé

Ao analisar as publicações é possível perceber que em todas as páginas ou perfis existe uma prioridade em fotografias sobre suas tradições, além da constante publicação de notícias e vídeos sobre a temática indígena. 
Figura 4 - Utilização de vídeos

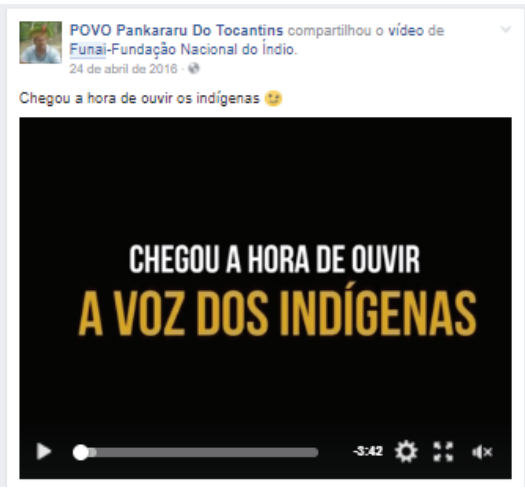

Fonte: Povo Pankararu do Tocantins

Para melhor entender os principais objetivos dessas redes sociais e ainda como estão propagando o ativismo digital indígena, elaborou-se o Quadro 3, que traz os "Principais assuntos" identificados. Essas categorias de análise, tais como "Tradições Indígenas", "Tecnologia", "Política", "Educação", "Demarcação de Terra", "Direitos Indígenas", "Saúde Indígena", "Esporte", "Meio Ambiente", e outros mencionados abaixo, justificam o ativismo indígena no ambiente digital em plena construção, em que estes indígenas criam um espaço de representações sobre suas tradições culturais, buscam a permanência dessas identidades e conexões com outros atores sociais, desta ou de outras expressões culturais, e fazem das redes sociais digitais, como o Facebook, aqui exemplificado, uma forma inovadora de falar sobre si, assumindo o papel político de fazer proliferar sentidos, modificar realidades ou rechaçar registros de suas tradições orais (KLEIN, 2013, p.36). 
Quadro 3: Principais assuntos identificados

\begin{tabular}{|c|c|}
\hline $\begin{array}{c}\text { Nome da Fan Page / } \\
\text { Perfil }\end{array}$ & $\begin{array}{l}\text { Principais assuntos* } \\
\text { (2014 a mai/2017) }\end{array}$ \\
\hline $\begin{array}{l}\text { Nação Xerente- } \\
\text { Tocantínia/TO }\end{array}$ & $\begin{array}{l}\text { Tradições Indígenas Xerente; } \\
\text { Tecnologia; Educação; Política; } \\
\text { Demarcação de Terra; Meio } \\
\text { Ambiente; Conflitos Agrários; } \\
\text { Esporte; Infraestrutura nas } \\
\text { aldeias; Saúde Indígena; Direitos } \\
\text { Indígenas. }\end{array}$ \\
\hline Povo Karajas & Tradições Indígenas Karajá; \\
\hline $\begin{array}{l}\text { Povo Pankararu do } \\
\text { Tocantins }\end{array}$ & $\begin{array}{l}\text { Direitos Indígenas; Tradições } \\
\text { Indígenas Pankararu; outros } \\
\text { assuntos sobre o Tocantins. }\end{array}$ \\
\hline Web Aldeias Xerente & $\begin{array}{l}\text { Saúde Indígena; Tradições } \\
\text { Indígenas Xerente; Rituais e } \\
\text { Artesanatos. }\end{array}$ \\
\hline Cultura \& Karajá & Iradições Indígenas Karajá; \\
\hline $\begin{array}{l}\text { Aldeia Canoanã } \\
\text { Javaé - Perfil }\end{array}$ & $\begin{array}{l}\text { Tradições Indígenas Javaé; } \\
\text { Direitos Indígenas, Política; } \\
\text { Educação. }\end{array}$ \\
\hline $\begin{array}{l}\text { Aldeia Salto Kripre - } \\
\text { Perfil }\end{array}$ & $\begin{array}{l}\text { Esporte; Tradições Indígenas } \\
\text { Xerente; Educação; }\end{array}$ \\
\hline
\end{tabular}

Fonte: Produzido pelos autores

Os conteúdos do item "Tradições Indígenas", mencionado em todas as páginas analisadas, referem-se justamente aos costumes, pinturas e rituais de cada povo analisado. Isto muitas vezes está relacionado ao fortalecimento de suas tradições e a busca por desmistificar o equívoco do "índio genérico", como se todas as

* Os assuntos foram inseridos na ordem dos mais citados para os menos citados. 
etnias fossem iguais (FREIRE, 2000). Mesmo não precisando provar isto, esses nativos querem "deixar justamente de sê-los [índios genéricos] ao afirmar sua especificidade, ao aprofundar os processos de diferenciação", (GONÇALVES, 2010, p. 98). Todavia, registram rituais e costumes específicos, selecionando, reconstruindo e fortalecendo manifestações culturais que, por vezes, "desejam preservar para as futuras gerações e, sobretudo, que elas julgam adequadas para se contrapor aos não índios. Neste segundo momento, a exigência de acesso à informação se completa com a exigência de comunicação" (GALLOIS e CARELLI, 1998, p.3).

Os principais assuntos publicados nessas redes são: tradições indígenas, tecnologias, educação, política, demarcação de terras, meio ambiente, conflitos agrários, esporte, infraestrutura nas aldeias, saúde indígena e direito dos indígenas (Quadro 3). A página "Nação Xerente- Tocantínia/TO", por sua vez, tem uma multiplicidade de conteúdos em torno também de reintegração de posse, desmatamento do cerrado demarcação de terras e conflitos agrários, assuntos estes que perpassam pelo ciberativismo.

Figura 5 - Notícia e reivindicações

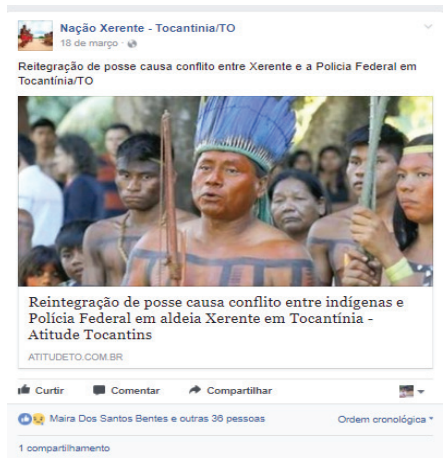

Fonte: Nação Xerente Tocantínia/TO
Figura 6 - Notícia e reinvidicações

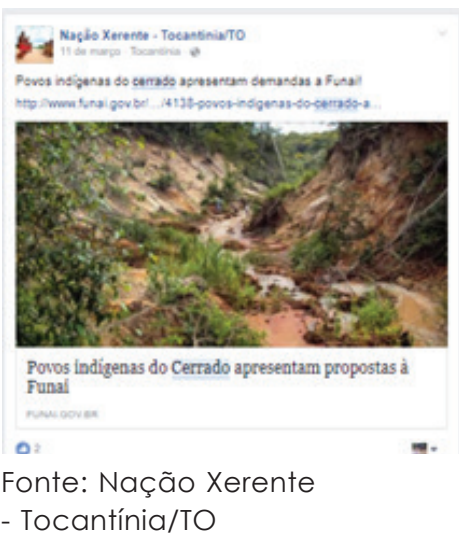


Percebe-se que os assuntos proporcionam um alcance maior, levando em conta as curtidas, comentários e compartilharmos, o que provoca, pois, a interatividade ${ }^{13} \mathrm{com}$ os internautas. O perfil "Aldeia Canoanã Javaé" está entre estes com uma participação expressiva dos internautas. Na figura abaixo trazem à tona a possível extinção da Fundação Nacional do Índio (FUNAI) e os comentários são diversos em torno do assunto.

Figura 7 - Exemplo de interatividade

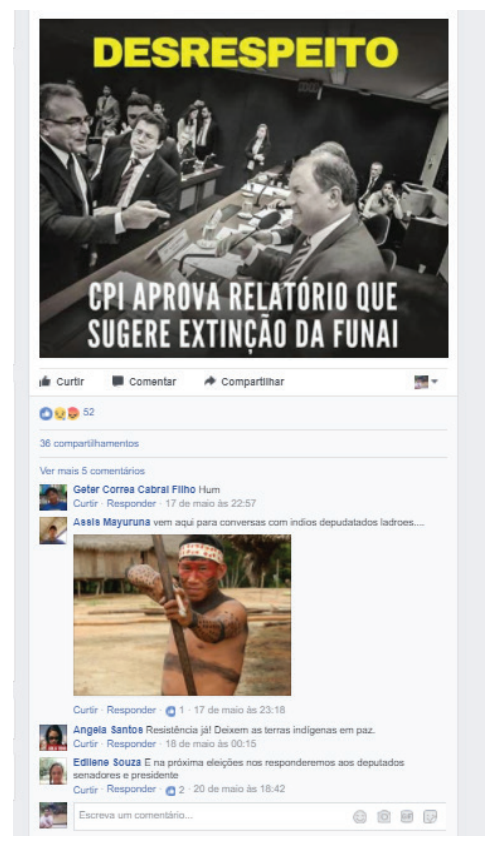

Fonte: Aldeia Canoanã Javaé

13 "Essas novas formas de sociabilização, mediadas pelas TIC, expõem traços e comportamentos de cada cultura. Até então, elas não eram mediadas por recursos tecnológicos não produzidos pelas próprias comunidades e, agora, formam um conjunto de sentidos só possíveis pela presença no ciberespaço na mediação pela Internet" (BITENCOURT, 2014, p.35). 
Deste modo, compreende-se que o ativismo é a busca de ideais e projetos em comum, com o intuito de provocar algum tipo de mudança socialmente. "No ativismo, opinamos, há maior exposição de elementos que compõem a faceta da identidade social e que estão relacionados (...) à faceta da identidade pessoal" (ROSA e SANTOS, 2013, p. 75).

Houve também participação dos indígenas do Tocantins e divulgação do Acampamento Terra Livre $(A T L)^{14}$, que realizou manifestações contra o governo brasileiro, e muitos dos protestos iniciaram-se e foram mobilizados na internet. Assim, posteriormente, realizaram um encontro às cegas entre si, reivindicando seus direitos (CASTELLS, 2013). Outro ponto que justifica o ciberativismo desses povos. "Essa forma de ativismo é realizada com a intenção de divulgar e abrir espaços para determinadas causas e possíveis discussões sobre os assuntos" (RESENDE et al, 2015, p.3)

Os indígenas do Tocantins constroem um espaço de representações sobre suas tradições culturais e buscam a preservação dessas identidades, divulgando não apenas temas em torno da cultura, mas dos seus principais anseios e lutas. Criam conexões com outros atores sociais, sejam desta ou de outras expressões culturais, pois essa é justamente uma das dinâmicas do espaço digital (LEMOS E LÉVY, 2010, p. 52). Tais transformações acarretaram novos contextos

14 É um evento nacional que reúne povos indígenas de todo o país para manifestar e discutir sobre temas relacionados aos nativos. Em 2017, 14 edição em Brasília (DF), mais de 4 mil indígenas realizaram protestos contra o Governo e a favor das políticas para os indígenas. Muitas das manifestações foram mobilizadas pela internet, seja na divulgação de sites de notícias ou em grupos do WhatsApp. Outras informações em: https://mobilizacaonacionalindigena.wordpress.com/ 
digitais, entre um clique e um curtir, entre um compartilhamento e um comentário, entre a necessidade de interagir e o anseio de valorizar suas tradições, e, sobretudo, em um ativismo constante pela democracia.

Figura 8 - Publicação sobre o ATL

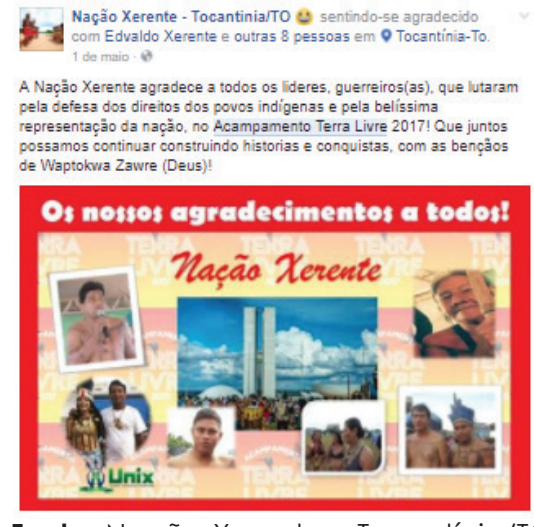

Fonte: Nação Xerente - Tocantínia/TO

\section{Considerações finais}

Ao ressignificar e redimensionar as suas tradições culturais com o viés da internet, os povos indígenas comprovam, também, que estão "ancorando" na cibercultura e no ciberativismo, até mesmo para divulgar aspectos da cultura e tradição indígena, além de expressarem os mais variados anseios na luta pela democracia e pela valorização dos seus povos. Assim, a comunicação mediada por computador proporciona que "essas interações sejam transportadas a um novo espaço, que é o ciberespaço, novas estruturas sociais e grupos que não poderiam interagir livremente tendem a surgir" (RECUERO, 2009, p. 89).

No Facebook, fica evidente por meio de uma análise de conteúdo de fanpages e perfis, que os povos indígenas do Tocantins encontraram um ca- 
nal direto de comunicação, interação, informação, conhecimento e principalmente porta-voz prático e acessível de seus anseios, onde podem mostrar suas diversidades culturais e dizer que são brasileiros, com os mesmos direitos de todos os outros povos. Porquanto, as pessoas, nas mais diversas diferenças culturais, ao se adaptarem ao universo digital, fazem existir uma circularidade nas informações, para que os processos sociais coletivos possam manter a estrutura social e as interações possam continuar acontecendo (RECUERO, 2009).

Ao partir das categorias levantadas por Vegh (2003), é possível ainda enquadrar o ciberativismo indígena do Tocantins, especialmente no que diz respeito à conscientização e apoio, visto que essas pessoas encontram na internet um ambiente de informação e discussão. Há ainda elementos de uma tímida organização e mobilização, já que nessa categoria os ativistas, ao se mobilizarem na internet, buscam determinadas ações. No entanto, para o enquadramento nessa categoria será necessário ainda um melhor amadurecimento da proposta que avança do universo online para o off-line.

Embora prevaleça a ideia de que, ao inserir tecnologias nas comunidades indígenas, se estaria destruindo as culturas destes povos, o artigo aponta que se trata de um equívoco ou um discurso reducionista. Assim, ressaltamos que essas populações "(...) passam por mudanças e influências exteriores, (...) buscam superar o estereótipo de que vivem em isolamento ou que representam um 'atraso', como costumam aparecer nos discursos da sociedade sobre os povos indígenas no Brasil" (LIMA e ARRAES, 2013, p. 4). E, por mais que prevaleça no discurso social o equívoco de 


\section{DA CIBERCULTURA AO CIBERATIVISMO: \\ OS POVOS INDÍGENAS DO TOCANTINS NO FACEBOOK}

que os indígenas são sinônimos de grupos com culturas congeladas, atrasadas e, assim, vivam em isolamento ${ }^{15}$, esses mesmos nativos vêm provando o contrário.

Portanto, a corrida de tora, as pinturas corporais, seus modos de organização, suas línguas e tantas outras tradições lidam agora com novas perspectivas da globalização e do capitalismo, mas continuam a existir e estão reafirmadas e ecoando na rede social.

\section{Referências}

BARDIN, Laurence. Análise de conteúdo. Lisboa: Edições 70. Tradução de Luís Antero Reta e Augusto Pinheiro. 1977.

BARTH, Frederick. Etnicidade e o conceito de cultura. In: Antropolítica: Revista Contemporânea de Antropologia e Ciência Política. N. 1. Niterói: EdUFF, 1995.

BAUMAN, Zygmuadt. De Peregrino à turista, o uma breve historia de La identidad. In: HALL, Stuart \& DU GAY, Paul. Cuestiones de Identidad cultural. Buenos Aires: Amorrortu, 2003.

CANCLINI, Néstor García. Culturas Híbridas - estratégias para entrar e sair da modernidade. Tradução de Ana Regina Lessa e Heloísa Pezza Cintrão. São Paulo: EDUSP, p. 283-350: Culturas híbridas, poderes oblíquos. 1997.

CASTELLS, Manuel. A Sociedade em rede. Paz e Terra, Volume I, 2001.

Redes de indignação e esperança: movimentos sociais na era da internet. Tradução Carlos Alberto Medeiros - ledRio de Janeiro: Zahar, 2013. 271p.

15 "(...) somos tentados a pensar que as sociedades indígenas de agora são a imagem do que foi o Brasil pré-cabralino, e que, como dizia Varnhagen, por razões diferentes, sua história se reduz estritamente à sua etnografia. (...) moldando unidades e culturas novas, cuja homogeneidade reside em grande parte numa trajetória compartilhada. (...) a ideia de isolamento deve ser usada com cautela em qualquer hipótese, pois há um contato midiatizado" (CUNHA, 2012, p.12). 
COELHO, Patrícia Margarida Farias; COSTAS, Marcos Rogério Martins. O ativismo digital - reflexões e apontamentos semióticos. 2013.

Teccogs São Paulo.

CUNHA, Manuela Carneiro da. Índios do Brasil: história, direitos e cidadania. São Paulo: Claro Enigma, $1^{a}$ ed. 2012.

DEMARCHI, André Luis Campanha. Kukràdjà Nhipêjx/Fazendo Cultura-Beleza, Ritual e Políticas da visualidade entre os Mebêngôkre -Kayapó. Tese de Doutorado. Rio de Janeiro. 2014. Disponível em < https://issuu.com/andredemarchi/docs/kukradja_nhipejx-fazendo_ cultura>. Acesso em 2 mai 2017.

FRAGOSO, S. Espaço, Ciberespaço, Hiperespaço. Textos de Comunicação e Cultura, n.42, UFBa, 2000.

FREIRE, José Ribamar Bessa. Cinco ldéias equivocadas sobre os índios. In Revista do Centro de Estudos do Comportamento Humano (CENESCH). Manaus-Amazonas, № 01 - Setembro, 2000. P.17-33.

GALLOIS, D. T.; CARELLI, V. "Índios eletrônicos": uma rede indígena de comunicação. In Sexta Feira. Antropologia artes humanidades, n. 2, São Paulo: Pletora. 2008. Disponível em < http://www.antropologia. com.br/tribo/sextafeira/pdf/num2/indio_elet.pdf> Acesso em 02 jun 2017.

GEERTZ, Clifford. A Interpretação das culturas. Rio de Janeiro. 2015.

GONÇALVES, Marco Antonio. Zonas de Contato: quando "cultura" se torna um conceito nativo (Os índios na contemporaneidade). In: Traduzir o outro: Etnografia e Semelhança. Rio de Janeiro: 7 Letras, 2010.

HALL, Stuart. A identidade cultural na Pós-modernidade. Rio de Janeiro: DP\&A, 2006.

LEMOS, André; LÉVY, Pierre. O Futuro da Internet: em direção a uma Ciberdemocracia planetária. São Paulo: Paulus. 2010.

LEMOS, André. Ciber-socialidade: tecnologia e vida social na cultura contemporânea. Revista Logos - Comunicação e Universidade. Faculdade de Comunicação Social - UERJ. Ano 4, número 6. 1997. 


\section{DA CIBERCULTURA AO CIBERATIVISMO: \\ OS POVOS INDÍGENAS DO TOCANTINS NO FACEBOOK}

. Ciber-Cultura-Remix. 2005. [s.l.: s.n.]. Disponível em: <http://www.facom.ufba.br/ciberpesquisa/andrelemos/remix.pdf>. Acesso em 13 mai de 2017.

. Espaço, mídia locativa e teoria ator-rede. Galaxia (São Paulo, Online), n. 25, p. 52-65, jun. 2013.

A comunicação das coisas: teoria ator-rede e cibercultura. São Paulo: Annablume, 2013.

LÉVY, Pierre. Cibercultura. Tradução de Carlos Irineu da Costa. São Paulo: Editora 34. 1999.

LIMA, Izaíra Thalita da Silva; ARRAES, Raoni Lourenço de. Índios na Rede: Um estudo sobre o ciberativismo indígena nas Redes Sociais Online. I Congresso Internacional de Net-ativismo da USP. 2013. Disponível em < https://netativismo.files.wordpress.com/2013/11/artigos-gt3.pdf > Acesso em 10 abr 2017.

MACHADO, Murilo Bansi. Entre o controle e o ativismo hacker: a ação política dos Anonymous Brasil. História, Ciências, Saúde - Manguinhos, Rio de Janeiro, v.22, supl., dez. 2015, p.1531- 1549. Disponível em: < http://www.scielo.br/pdf/hcsm/v22s0/0104-5970-hcsm22-s1-1531.pdf>. Acesso em 15 jul 2017.

PEREIRA, Eliete da Silva. Ciborgues Indígen@as.br: a presença nativa no ciberespaço. Dissertação de Mestrado. Centro de Pesquisa e Pós-graduação das Américas, Instituto de Ciências Sociais, Universidade de Brasília, 2007. 169p.

. Ciborgues indigen@s.br: entre a atuação nativa no ciberespaço e as (re) elaborações étnicas indígenas digitais. In: II SIMPÓSIO NACIONAL DA ABCIBER, 2008, São Paulo. Anais eletrônicos. Disponível em: < http://www.cencib.org/simposioabciber/PDFs/CC/Eliete\%2OPereira.pdf >. Acesso em 12 jun 2017.

- O local digital das culturas: As interações entre culturas, mídias digitais e territórios. 2013. 295 f. Tese (Doutorado) - Escola de Comunicações e Artes de São Paulo, Universidade de São Paulo, São Paulo, 2013. Disponível em < www.teses.usp.br/ teses/disponiveis/27/27154/tde-06052014.../ElietePereira.pdf>. Acesso em 16 out 2017. 
RESENDE, Tamires Parreira; FREITAS, Yarim Mayma Ferreira; OLIVEIRA, Pedro Pinto de. Ciberativismo Nas Redes Sociais: Compartilhando Mudanças. Intercom - Campo Grande - MS. 2015.

RECUERO, Raquel da Cunha. Redes sociais na internet. Porto Alegre: Sulina, 2009.

RIGITANO, Maria Eugenia Cavalcanti. Redes e ciberativismo: notas para uma análise do centro de mídia independente. I Seminário Interno do Grupo de Pesquisa em Cibercidades, FACOM-UFBA. Outubro de 2003.

ROSA, Gabriel Arthur Marra e; SANTOS, Benedito Rodrigues dos. Facebook e as nossas identidades virtuais. Brasília: Thesaurus, 2013. $200 \mathrm{p}$.

ROSSINI, Patricia G. C.. Das redes para as ruas: mídias sociais como "armas" na luta por reconhecimento. Comunicação \& Sociedade: Revista do Programa de Pos-Graduação em Comunicação da Universidade Metodista de São Paulo. São Bernardo do Campo, v. 36, n.1, p. 301-325, jul.-dez 2014.

RÜDIGER, Francisco. Cultura e Cibercultura: princípios para uma reflexão crítica. In O Estatuto da Cibercultura no Brasil, Vol. 34, Nº1, $1^{\circ}$ semestre 2011 .

SAHLINS, Marshal. O "pessimismo sentimental" é a experiência etnográfica: por que a cultura não é um "objeto" em via de extinção. In: Mana v. III n. 1, 1997.

SÁNCHEZ, Waldo Lao Fuentes. O movimento zapatista: Na construção da sua autonomia. 2015. Disponível em: < http://www.revistas. usp.br/diversitas/article/download/113948/111797>. Acesso em 13 maio 2017.

SANTAELLA, Lúcia. Da cultura das mídias à cibercultura: o advento do pós-humano. Revista FAMECOS: Porto Alegre, $n^{\circ} 22$, dezembro 2003.

THOMPSON, John B. A mídia e a modernidade: uma teoria social da mídia. Petrópolis, RJ: Vozes, 2008.

VEGH, Sandor. Classifying forms of online activism: the case of cyberprotests against the World Bank. In: MCCAUGHEY, M., AYERS, M.D. 


\section{DA CIBERCULTURA AO CIBERATIVISMO: \\ OS POVOS INDÍGENAS DO TOCANTINS NO FACEBOOK}

(ed.). Cyberactivism: online activism in theory and practice. London: Routledge, 2003.

\section{Elvio Juanito Marques de Oliveira Júnior}

É graduado em Comunicação Social - Jornalismo, pós-graduado em Ensino de Comunicação: Estudos contemporâneos (2016) e Mestre em Comunicação e Sociedade (2018), ambos pela Universidade Federal do Tocantins (UFT). Atualmente é pós-graduando em Comunicação Empresarial e Marketing Digital pela Unicesumar.

\section{Liana Vidigal Rocha}

Doutora em Ciências da Comunicação pela ECA/USP. Docente do Curso de Jornalismo e do Programa de Pós-graduação em Comunicação e Sociedade da Universidade Federal do Tocantins. Líder do Grupo de Pesquisa em Jornalismo e Multimídia (CNPq). 